\title{
EMBEDDED BASED SENSORLESS CONTROL OF PMBLDC MOTOR WITH VOLTAGE CONTROLLED PFC CUK CONVERTER FOR AN AIR CONDITIONER
}

\author{
Tinu Francis ${ }^{1}$, P.Gokula Krishnan ${ }^{2}$ \\ ${ }^{1} P G$ Scholar, Department of EEE, SNS College of Engineering, Coimbatore, India \\ ${ }^{2}$ Assistant Professor, Department of EEE, SNS College of Engineering, Coimbatore, India
}

\begin{abstract}
This paper develops a brushless DC motor control technique without using any sensors. Back emf of motor is considered as a parameter for commutation. Also this system incorporates cuk converter as a power factor correction converter for PMBLDC motor fed through a diode bridge rectifier from a single phase AC mains. Three phase VSI is used in this system as an electronic commutator for BLDC motor based compressor in an air conditioner. Here the proportionality between Dc link voltage and speed is considered and speed control in this system is attained by maintaining this proportionality. Wide range speed control is possible by controlling the dc link voltage. Proposed system is designed, modelled and simulated in a Matlab environment and evaluatory analysis of system is done.
\end{abstract}

Keywords - PMBLDC,PFC,Cuk Converter,Sensorless control ,Back EMF Detection, Zero crossing.

\section{INTRODUCTION}

PMBLDC motor is being replaced in many of the industrial application because of its features of high efficiency, wide speed range, and low maintenance. Now a days PMBLDC motor which is having comparable characteristics with both DC motor and induction motor is widely used in industries since it is capable to solve the energy crisis to an extend.Because of high starting torque,wide speed range,constant torque etc. BLDC motor is having comparable characteristics with DC motor.But its features of mechanical commutator and brushes reduces the efficiency and perfomance.Also PMBLDC motor is suited for low power applications where other $\mathrm{AC}$ motors are normally being used in high power applications.Combined features of $\mathrm{AC}$ and $\mathrm{DC}$ motors along with solution to its drawbacks make PMBLDC Motor a suitable choice for fast growing industrial applications. For the past two decades several Asian countries such as Japan, which have been under pressure from high energy prices, have implemented variable speed PM motor drives for energy saving applications such as air conditioners, refrigerators, washing machines, dishwashers, high-end pumps, fans, and other appliances that require high reliability and efficiency.Problems associated with cost and reliability of rotor position sensors have motivated research in the area of position sensorless BLDC motor drives .

Sanjeev Singh and Bhim Singh proposes a system[ 7] with PFC which uses hall sensor for commutating PMBLDC motor. But use of hall sensor makes the system more costlier and les reliable.Back EMF estimation methods typically rely on the zero crossing detection of the EMF waveform. The technique of estimating back EMF by sensing the terminal voltages with respect to a virtual neutral point is proposed in [5]. The neutral point will not be stable during pulse width modulation (PWM) switching. Low pass filters have been used to eliminate the higher harmonics and to convert the terminal voltages into triangular waveform signals.

So a delay is introduced in the sensed signal,which also varies with the operating speed. Therefore, this method is well suited only for a narrow speed range.Indirect back EMF sensing technique is proposed in [4] without the need of neutral or virtual neutral potential. The back EMF zero crossing is sensed with respect to the negative dc bus potential. In [12], Kim and Ehsani define a function depending on the measured voltages, currents, and the derivative of the currents, which indicates the switching instants. Since their functions are dependent on the computation of derivatives of currents, the method requires digital implementation and could be affected by sensor noise. Ogasawara and Akagi [10],uses sensorless control but detected the zero-crossing of back EMF by the first non-zero current pulse after the free-wheeling period of the floating phase. Detecting the free-wheeling diode conduction in the open phase gives the zero-crossing point of the back EMF waveform .This approach of rotor-position sensing works over a wide speed range, especially at lower speed. The main drawback of this scheme is the requirement of six additional power supplies for the comparator circuits to detect current flowing through the free-wheeling diode.

In this paper a simple method of zero crossing detection of back emf is introduced by considering back emf difference. PMBLDC Motor being a nonlinear load when connected to AC supply voltage and current harmonics will be produced which increase power losses and, therefore, have a negative 
impact on electric utility distribution systems and components. The PMBLDCMD is fed from a single-phase ac supply through a Diode Bridge Rectifier (DBR) followed by a capacitor at dc link. It draws a pulsed current with a peak higher than the amplitude of the fundamental input current at ac mains due to an uncontrolled charging of the dc link capacitor. This results in poor Power Quality (PQ) at ac mains in terms of poor power factor (PF) of the order of 0.728, high Total Harmonic Distortion (THD) of ac mains current at the value of $81.54 \%$, and high crest factor (CF) of the order of 2.28. Therefore, a PF correction (PFC) converter among various available converter topologies is almost inevitable for a PMBLDCMD. Moreover, the PQ standards for low power equipments, such as IEC 61000-3-2, emphasize on low harmonic contents and near unity PF current to be drawn from ac mains by these drives. This paper proposes a voltage controlled PFC Cuk converter for sensorless PMBLDC motor for improving PF and THD value.

\section{SYSTEM DESCRIPTION}

Dc supply is obtained from AC source after rectification. Rectified DC is fed to DC to DC cuk converter and thus required input voltage for VSI is obtained. Three phase supply for PMBLDC motor is obtained from VSI. Back emf is detected and its zero crossing is identified and according to this a switching sequence generator is designed and sequential switching pulses are given to VSI which will act as an electronic commutator of PMBLDC motor. The proposed system is meant for PFC in sensorless PMBLDC motor. The System consist of two main parts a PFC Cuk Converter and Sensorless controlled PMBLDC Motor.

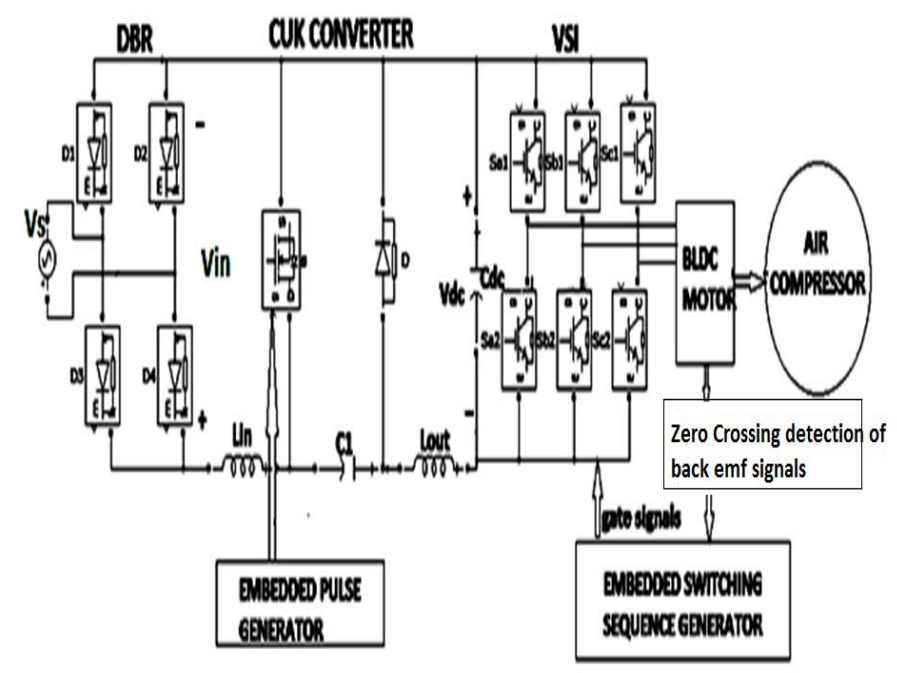

Fig -1: Circuit Diagram of Proposed system

Circuit diagram of the proposed system is given in Fig.1. The Cuk dc-dc converter controls the dc link voltage using capacitive energy transfer which results in non pulsating input and output currents. The proposed PFC converter is operated at a high switching frequency for fast and effective control with additional advantage of a small size filter. For high-frequency operation, a metal-oxide-semiconductor field-effect transistor (MOSFET) is used in the proposed PFC converter. Embedded pulse generator controls MOSFET switch of cuk converter. PMBLDC motor make use of sensorless control with back emf and its zero crossing detection.

\section{SENSORLESS CONTROL}

A new sensorless drive scheme for BLDC motor is used in this system where motor commutation control is obtained by detecting zero crossing point of back emf which one of the simplest method of sensorless control. But exact current commutation point is obtained after a shift from this zero crossing point. In order to avoid this phase shift this circuit make use of difference of back emfs between two consecutive phases. Zero crossing point of this back emf difference waves is exactly at current commutation point ant so commutation can be successfully controlled in this proposed circuit by finding out the zero crossing point of back emf difference waveform. When the motor is at a standstill or low speed, back-EMF is zero. So at starting an external triggering block is introduced to provide initial triggering pulses so that motor starts running. So back emf is now produced and can be sensed directly. After that difference of back emf between two consecutive phases is found.

Zero crossing points of three phases is detected in zero crossing detection block by means of embedded coding. Appropriate switching sequence for VSI is made based on zero crossing points of back emf difference between two phases. Zero crossing points of back emf difference and hall signal states of corresponding phases are equal. So depending on zero crossing point $\mathrm{ON}$ - OFF stages similar to hall sensor states are coded. Corresponding to these ON-OFF conditions of each phase Embedded Switching Sequence Generator is coded to produce sequential switching for VSI.Speed of motor is proportional to dc link voltage and speed control of system is done by controlling the DC link voltage obtained from cuk converter.

\section{SYSTEM MODELLING}

\subsection{Cuk Converter}

The proposed PFC Cuk dc-dc converter controls the dc link voltage using the equation

$$
V_{d c}=\frac{V_{i n} \boldsymbol{D}}{1-D}
$$

Where $V_{\text {in is }}$ the average output of the DBR for a given ac input voltage $\left(\mathrm{V}_{\mathrm{s}}\right)$ related as

$$
V_{i n}=\frac{2 \sqrt{2}}{\pi} V_{s}
$$

The cuk converter uses a boost inductor $\left(\mathrm{L}_{\mathrm{i}}\right)$ and a capacitor $\left(\mathrm{C}_{1}\right)$ for energy transfer. Their values are given as 


$$
\begin{gathered}
L_{i n}=\frac{D V_{i n}}{f_{s}\left(\Delta I_{\text {Lin }}\right)} \\
C_{i n}=\frac{D I_{d c}}{f_{s} \Delta V_{c i n}}
\end{gathered}
$$

Where $\Delta I_{\text {Lin }}$ is a specified inductor current ripple, $\Delta V_{c 1}$ is a specified voltage ripple in the intermediate capacitor $(C 1)$, and $I_{d c}$ is the current drawn by the PMBLDCM from the dc link. A ripple filter is designed for ripple-free voltage at the $\mathrm{dc}$ link of the Cuk converter. The inductance $(L o)$ of the ripple filter restricts the inductor peak-to-peak ripple current $\left(\Delta I_{\mathrm{Lo}}\right)$ within a specified value for the given switching frequency $(f s)$, whereas the capacitance $(C d)$ is calculated for the allowed ripple in the dc link voltage $\left(\Delta V_{\mathrm{Cd}}\right)$ [7], [8]. The values of the ripple filter inductor and capacitor are given as

$$
\begin{gathered}
L_{\text {out }}=\frac{(1-D) V_{d c}}{f_{s} \Delta I_{\text {lout }}} \\
C_{d}=\frac{I_{d c}}{2 \omega \Delta V_{c d}}
\end{gathered}
$$

The PFC converter is designed for a base dc link voltage of $V_{\mathrm{dc}}=298 \mathrm{~V}$ at $V_{s}=220 \mathrm{~V}$ for $f_{s}=40 \mathrm{kHz}, I_{s}=4.5 \mathrm{~A}, \Delta I_{\mathrm{Li}}=$ $0.45 \mathrm{~A}\left(10 \%\right.$ of $\left.I_{\mathrm{dc}}\right), I_{\mathrm{dc}}=3.5 \mathrm{~A}, \Delta I_{\mathrm{Lo}}=3.5 \mathrm{~A}\left(\approx I_{\mathrm{dc}}\right), \Delta V_{\mathrm{Cd}}=4$ $\mathrm{V}\left(1 \%\right.$ of $\left.V_{o}\right)$, and $\Delta V_{\mathrm{C} 1}=220 \mathrm{~V}\left(\approx V_{s}\right)$. The design values are obtained as $L_{i}=6.61 \mathrm{mH}, C_{1}=0.3 \mu \mathrm{F}, L_{o}=0.82 \mathrm{mH}$, and $C_{d}$ $=1590 \mu \mathrm{F}$.

\subsection{PMBLDC Motor Drive}

Equivalent Circuit of VSI fed PMBLDC motor is shown in Fig.4.For BLDC motor VSI plays the role of electronic commutator. Six-step commutation is a cost-effective due to its simple and relatively inexpensive feedback The output of VSI to be fed to phase "a" of the PMBLDC motor is calculated from the equivalent circuit of a VSI-fed PMBLDCM shown in Fig. 2 as

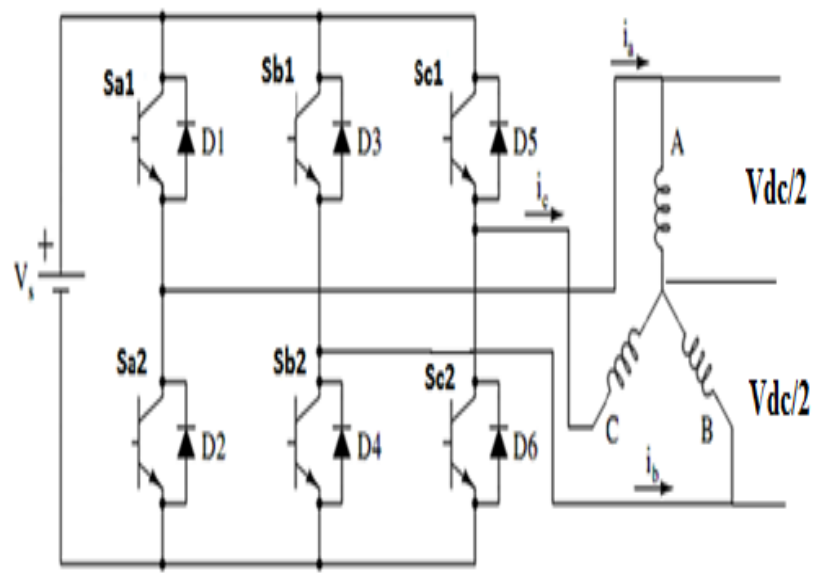

Fig.2 VSI fed PMBLDC Motor
When Sa1=1,

$V_{a 0}=\frac{V_{d c}}{2}$

When $\mathrm{Sa} 2=1$

$V_{a 0}=-\frac{V_{d c}}{2}$

When $\mathrm{Sa} 1=\mathrm{Sa} 2=0$,

$$
V_{a 0}=0
$$

Where $v_{\mathrm{ao}}, v_{\mathrm{bo}}, v_{\mathrm{co}}$, and $v_{\text {no }}$ are the voltages the three phases $(\mathrm{a}, \mathrm{b}$, and $\mathrm{c}$ ) and neutral point (n) with respect to the virtual midpoint of the dc link voltage shown as "o" in Fig.2. The voltages $v_{\mathrm{an}}, v_{\mathrm{bn}}$, and $v_{\mathrm{cn}}$ are the voltages of the three phases with respect to the neutral terminal of the motor (n), and $V_{\mathrm{dc}}$ is the dc link voltage. The values 1 and 0 for $S_{\mathrm{a} 1}$ or $S_{\mathrm{a} 2}$ represent the "on" and "off" conditions of respective IGBTs of the VSI. The voltages for the other two phases of the VSI feeding the PMBLDC motor, i.e., $v_{\mathrm{bo}}, v_{\mathrm{co}}, v_{\mathrm{bn}}$, and $v_{\mathrm{cn}}$, and the switching pattern of the other IGBTs of the VSI

Differential equations governing PMBLDC is given as

$$
\begin{gathered}
V_{a n}=R i_{a}+p \lambda_{a}+e_{a n} \\
V_{b n}=R i_{b}+p \lambda_{b}+e_{b n} \\
V_{c n}=R i_{c}+p \lambda_{c}+e_{c n}
\end{gathered}
$$

Where $\lambda_{\mathrm{a}}, \lambda_{\mathrm{b}}, \lambda_{\mathrm{c}}$ are flux linkages and they are given by

$$
\begin{aligned}
& \lambda_{a}=L_{s} i_{a}-M\left(i_{b}+i_{c}\right) \\
& \lambda_{b}=L_{s} i_{b}-M\left(i_{a}+i_{c}\right) \\
& \lambda_{c}=L_{s} i_{c}-M\left(i_{b}+i_{a}\right)
\end{aligned}
$$

Where Ls indicates self-inductance and $\mathrm{M}$ indicates mutual inductance of PMBLDC motor windings.

Torque developed by motor is given by the equation

$$
T_{e}=\frac{\left(e_{a} n i_{a}+e_{b} n i_{b}+e_{c} n i_{c}\right)}{\omega_{r}}
$$




\section{RESULTS AND DISCUSSION}

\subsection{Comparison of Hall Sensor Signals with Back}

\section{EMF Difference Waveforms}

ON-OFF timings of hall signals and phase difference waveforms of BLDC motor is find to be similar so back emf difference waveforms are considered for developing sensorless commutation in this system. A sensorless technique is developed such that zero crossing point of phase difference is considered and for determining the rotor position and thus the firing pulses to the VSI inverter can be controlled. Compared signals is shown in Fig.3

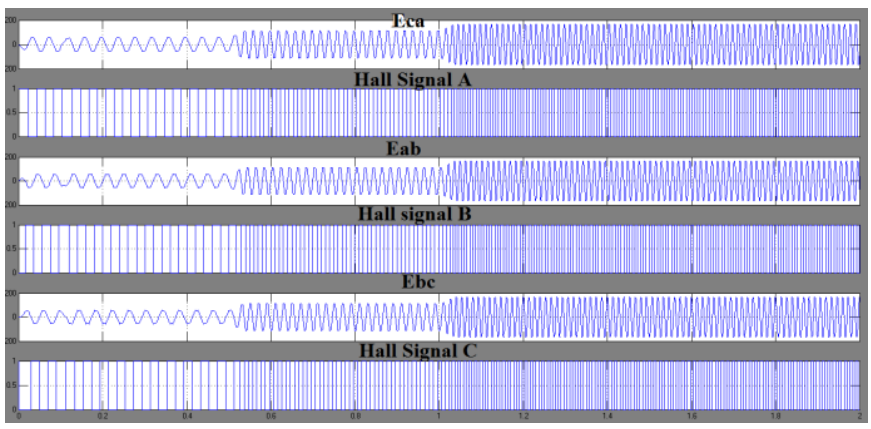

Fig.3 Hall signals and phase voltage difference waveforms

\subsection{System Simulink Model}

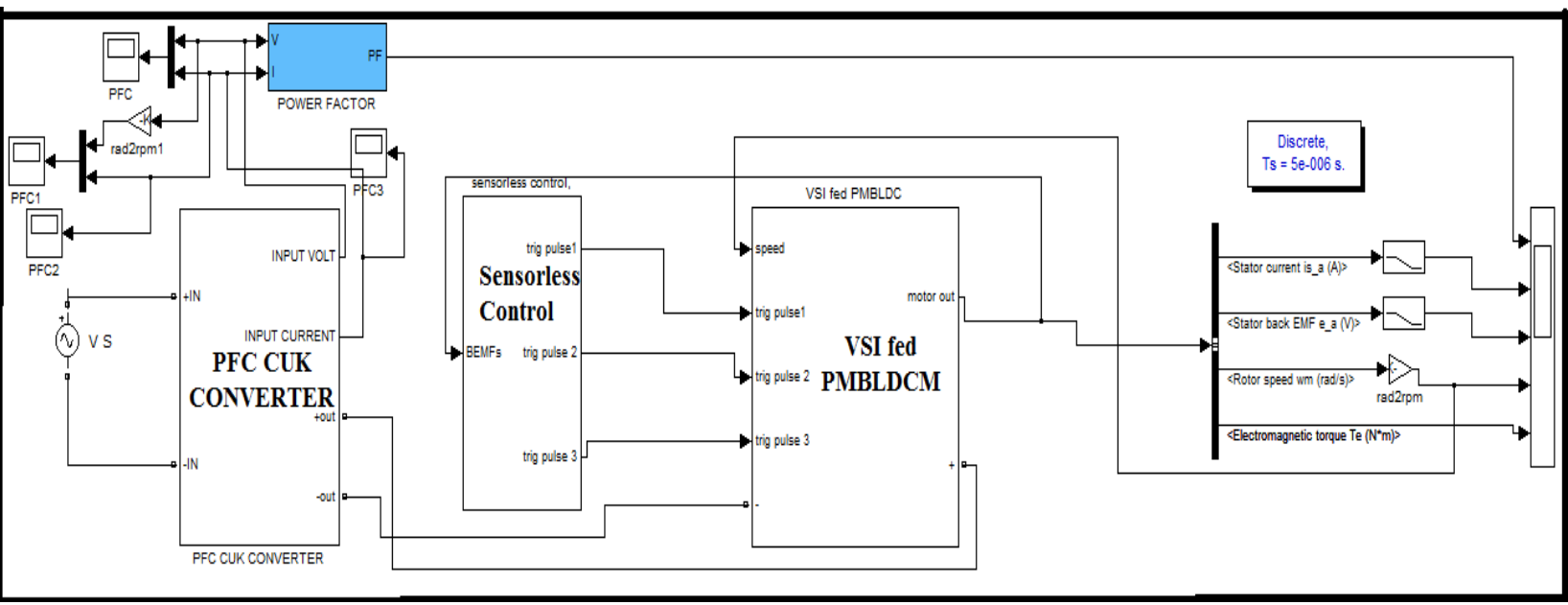

Fig -4 Simulink Model of Proposed System

\subsubsection{VSI fed PMBLDCM with Sensorless Control}

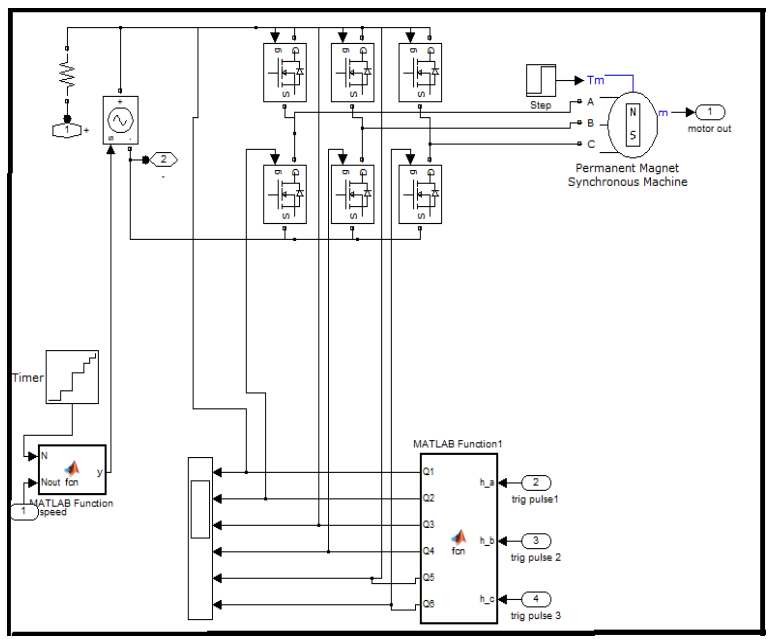

Fig -5 VSI Fed PMBLDC Motor

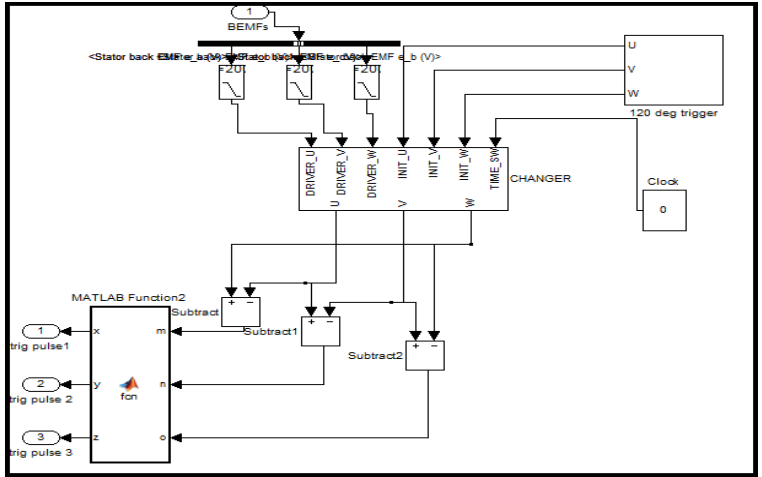

Fig -6 Sensorless Control in PMBLDCM

Controlled voltage according to speed is Supplied to PMBLDC motor is through a VSI.VSI plays a role of electronic commutator in this system. Switching pulses to six IGBT of VSI is given by an Embedded Switching Sequence Generator. Input to this block is from sensorless control block shown in Fig 6. Phase difference waveforms of back EMF between three phases is obtained and its zero crossing points are determined by a zero crossing detector. An initial external triggering has to be given to the motor for obtaining initial back emf with the help of a changer block. Output signals of zero crossing detector is equivalent to hall sensor 
signals of motor commutation. So this signals can be given as input to Embedded pulse generator for VSI.

\subsubsection{PFC in PMBLDC Motor System}

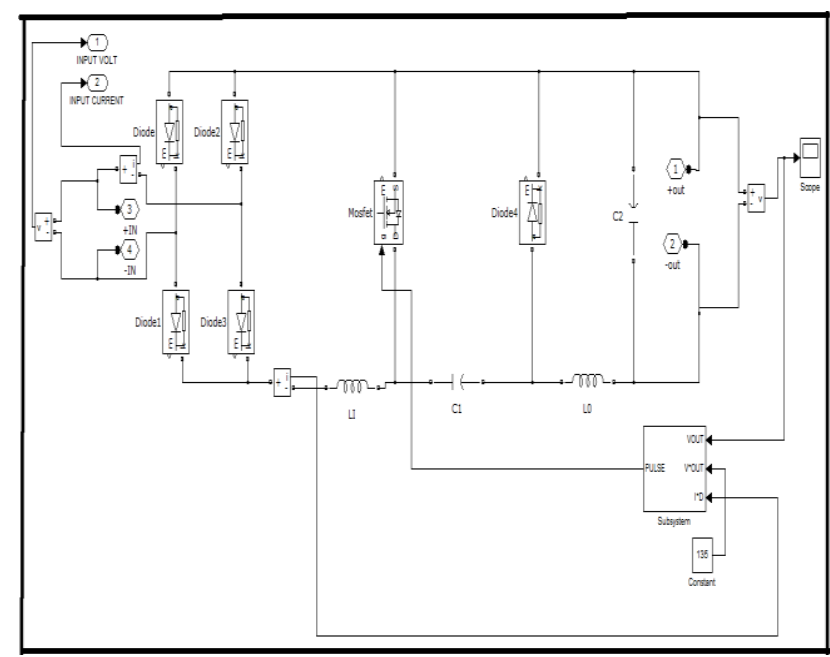

Fig -7 PFC Cuk Converter for PMBLDC Motor System

PMBLDC Motor when connected to AC supply system will be distorted with harmonics and other distortions. This problem can be solved to an extend and PF and THD value of system can be improved by incorporating a PFC Cuk converter. Speed of the motor in this system is controlled by controlling DC link voltage which is the output voltage of cuk converter. Switching pulses to the mosfet are controlled in such a way to maintain the dc link voltage constant at required level in spite of speed variation occurred in the system.

\subsection{Simulation Results}

\subsubsection{Input and output Waveforms of Cuk}

\section{Converter}
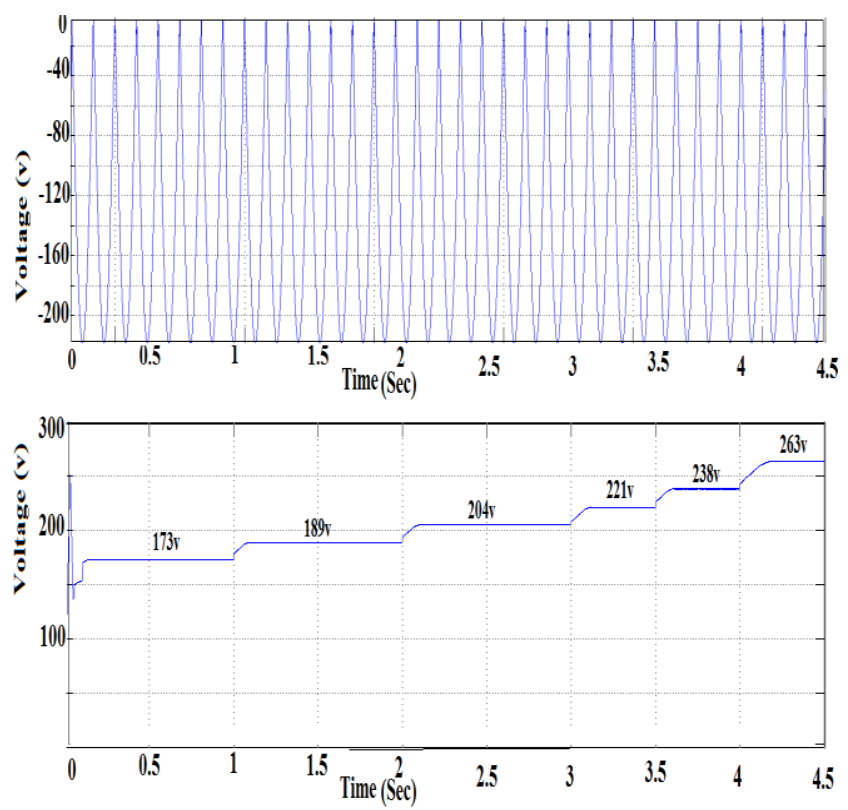

Fig -8 Input and Output Voltage Waveforms of Cuk Converter
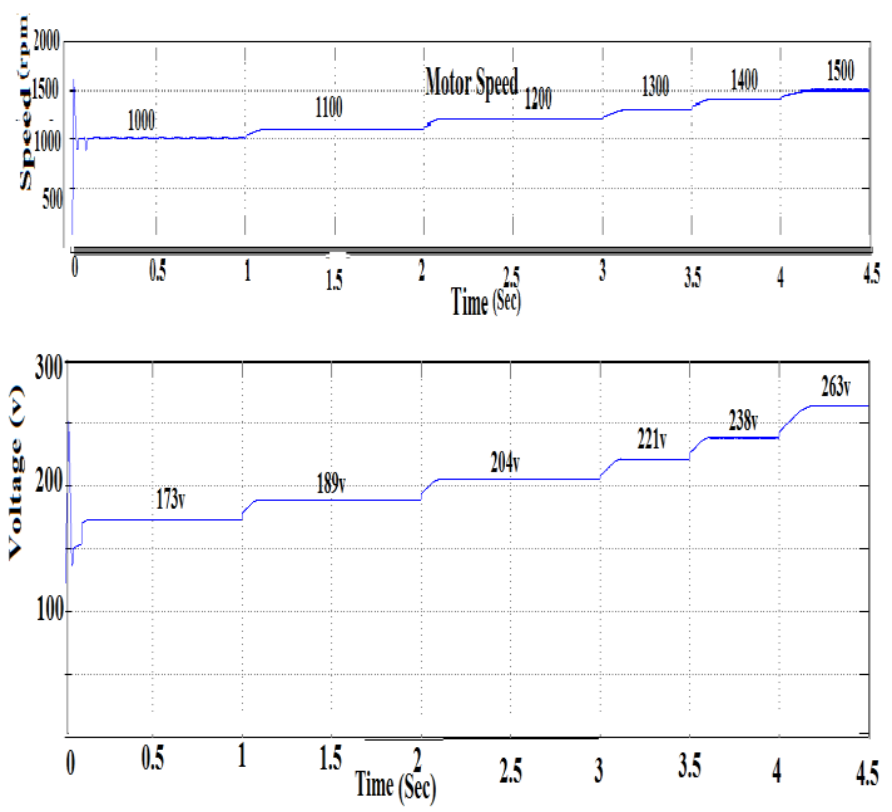

Fig -9 Dc Link Voltage Levels for different Speed Levels

Rectified output, i.e. pulsating DC is given as input to cuk converter. Designed inductor and capacitor value and the required pulses to mosfet in a cuk converter combine together to give constant DC output which is required for VSI as input voltage. In fig $8 \mathrm{Dc}$ link voltage is adjusted at six levels to get six different levels of speed. Dc link voltage and Speed acquired by corresponding voltage is shown in Fig.9.

\subsubsection{Performance Characteristics of PMBLDC}

\section{Motor at no Load}
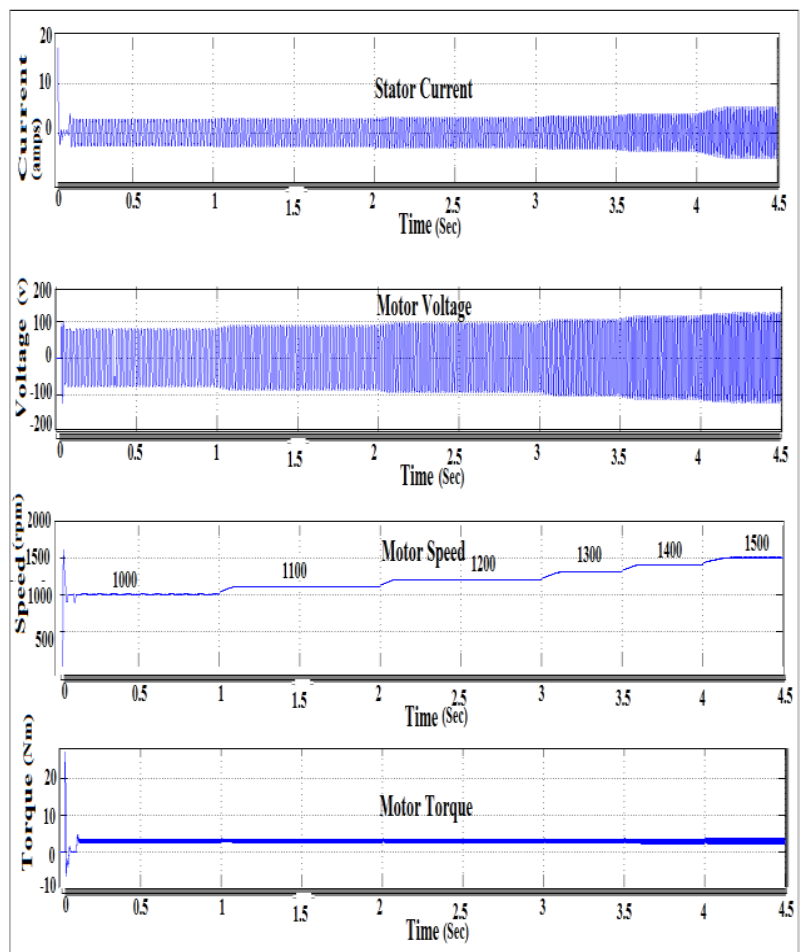

Fig.10 Performance Characteristics of PMBLDC Motor a)Stator Current b)Motor Voltage c)Speed d)Torque 
Performance of PMBLDC Motor is analysed by its stator current, Voltage, Speed and Torque characteristics and is shown in Fig 10. From the characteristics it is observed that, torque remains constant at varying speed conditions, Stator current value increases with increase in speed, Voltage across the motor increases with increase in speed.

A stable operation of PMBLDC motor is obtained in this proposed system since stator current developed in this motor maintains almost constant range of value. This results in constant torque operation even under varying speed conditions.

\subsubsection{PF and THD Value of the System}

$\mathrm{PF}$ value of system at various speed conditions is observed and observed as 0.9992 at rated speed. As the speed increases PF shows slight improvement in its value. Thus the system is capable of attaining a PF of about unity and it is shown in Fig.6.9.THD value for the proposed system is attained as $2.56 \%$ at rated speed and is satisfying the IEEE standards.

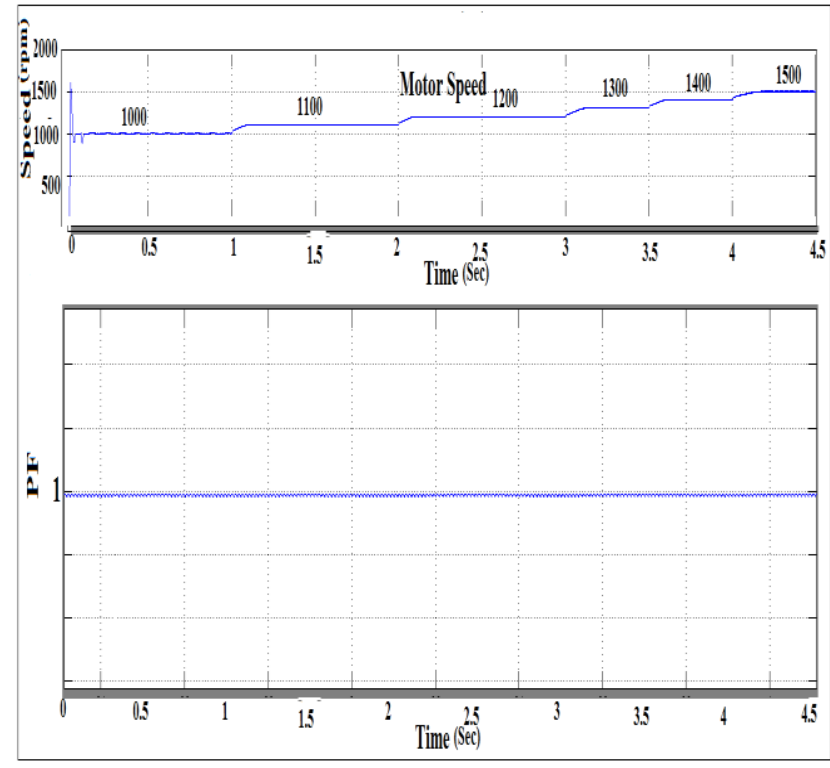

Fig -12 PF value at various speeds

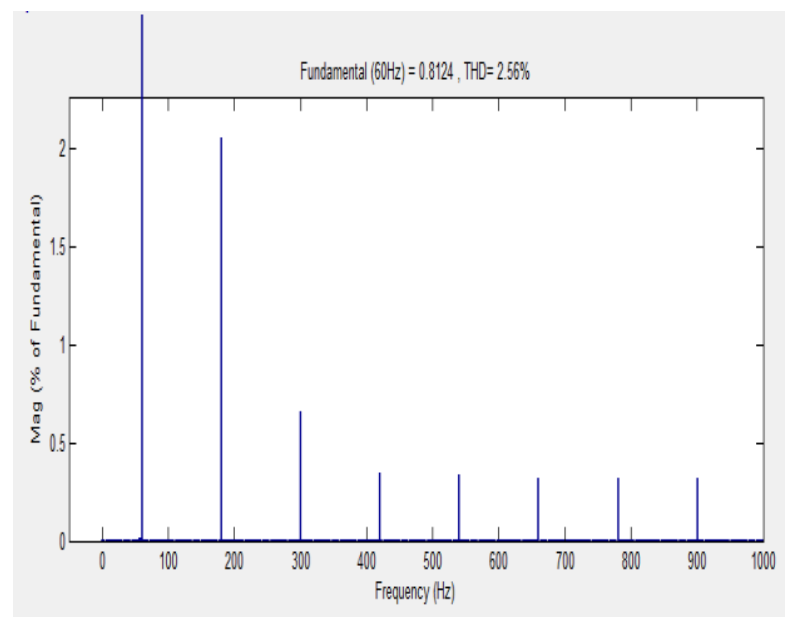

Fig -13 THD Value of the System

\subsection{Tabulation of Results}

Motor is controlled at speeds from $300 \mathrm{rpm}$ to $1500 \mathrm{rpm}$, its rated speed, and corresponding DC link voltage, Stator current, PF value and THD value is evaluated in Table.6.1.An input of $62 \mathrm{v}$ is required to get 300rpm speed and input dc link voltage proportionally increased to get higher values of speed values and $263 \mathrm{v}$ is applied to get a $1500 \mathrm{rpm}$ speed. i.e. in order to obtain a speed up to 1200 rpm buck action and above that boost action is done by the cuk converter. It is observed that PF value varies from 0.991 at $300 \mathrm{rpm}$ to 0.9992 at $1500 \mathrm{rpm}$ indicating the $\mathrm{PF}$ improvement towards rated speed. THD value of the system also improves from 5.2 at $300 \mathrm{rpm}$ to $2.56 \%$ at rated speed indicating improvement in THD value in this system.

Table.1 Performance Evaluation of PMBLDC Motor at Various Speeds

\begin{tabular}{|c|c|c|c|c|c|}
\hline $\begin{array}{c}\text { Vdc (V) } \\
\text { (cuk converter } \\
\text { output) }\end{array}$ & $\begin{array}{c}\text { Speed } \\
\text { (rpm) }\end{array}$ & $\begin{array}{c}\text { Stator } \\
\text { current } \\
\text { Is (Amps) }\end{array}$ & $\begin{array}{c}\text { Torque } \\
\text { (Nm) }\end{array}$ & PF & $\begin{array}{c}\text { THD } \\
\text { Value } \\
(\%)\end{array}$ \\
\hline 62 & 300 & 2.1 & 3.5 & 0.991 & 5.2 \\
\hline 78 & 400 & 2.2 & 3.5 & 0.983 & 5.10 \\
\hline 94 & 500 & 2.2 & 3.5 & 0.96 & 4.94 \\
\hline 110 & 600 & 2.2 & 3.5 & 0.95 & 4.80 \\
\hline 126 & 700 & 2.3 & 3.5 & 0.98 & 4.60 \\
\hline 141 & 800 & 2.3 & 3.5 & 0.9990 & 4.54 \\
\hline 157 & 900 & 2.4 & 3.5 & 0.9991 & 4.48 \\
\hline 173 & 1000 & 2.5 & 3.5 & 0.9991 & 4.12 \\
\hline 189 & 1100 & 2.8 & 3.5 & 0.9992 & 3.36 \\
\hline 204 & 1200 & 3 & 3.5 & 0.9992 & 2.77 \\
\hline 221 & 1300 & 3.3 & 3.5 & 0.9992 & 2.38 \\
\hline 238 & 1400 & 3.8 & 3.5 & 0.9992 & 2.33 \\
\hline 263 & 1500 & 5.2 & 3.5 & 0.9992 & 2.55 \\
\hline
\end{tabular}

\section{CONCLUSIONS}

A new speed control strategy for a sensorless PMBLDC motor has been developed in this paper. A PFC has been achieved for this system by means of a cuk converter. Smooth speed control is achieved in this system by means of DC link voltage control. Also the system is able to control motor at different speeds by controlling the DC link voltage which enables speed control in system as per the requirement of application especially in achieving air conditioning as per temperature alteration. Introduction of PFC cuk enables the system to attain a PF of around unity and THD value of $2.56 \%$ is achieved by this system which is within IEEE standards. 


\section{REFERENCES}

[1] C. Wang (2004), "A novel approach for sensorless control of PM machines down to zero speed without signal injection or special PWM technique," IEEE trans. J. Power electronics, vol.19, no. 6, pp. 16011607

[2] George, G.J., Rakesh, R.Arun,(2012),.PMBLDC motor drive with Power Factor correction controller, pp63 - 68, Computing, Electronics and Electrical Technologies (ICCEET) International Conference,

[3] Huai Wei, IEEE,(1998),Comparison of Basic Converter Topologies for Power factor Correction, Southeastcon '98. Proceedings. IEEE pp348 - 353, ISBN 0-7803-4391-3.

[4] J.Shao,D.Nolan,M.Teissier, and D.Swanson,2003,A novel microcontroller based sensorless brushless DC (BLDC) motor drive for automotive fuel pumps, IEEE Trans. Ind. Appl., vol. 39, no. 6, pp. 1734-1740.

[5] K.Iizuka, H.uzuhashi, M.Kano, T.Endo,(1985), Microcomputer control for sensorless brushless motor, IEEE trans. Ind. Appl., vol. Ia-21, no. 4, pp. 595-601.

[6] P. Damodharan And Krishna Vasudevan,(2010), Sensorless brushless dc motor drive based on the zerocrossing detection of back electromotive force from the line voltage difference, IEEE transactions on energy conversion, vol. 25.

[7] P. Pillai and R.Krishnan,( 1989), Modelling, simulation, and analysis of permanent-magnet motor drives, IEEE trans. Ind. Appl, vol. 25, no. 2, pp.265279.

[8] Sanjeev Singh, member IEEE, and Bhim Singh, fellow IEEE,(2012),A voltage controlled PFC cuk converter-based PMBLDCM drive for airconditioners", IEEE transactions on industry applications, vol. 48, no. 2.

[9] S. Ogasawara and H. Akagi,(1991),An approach to position sensorless drive for brushless dc motors, IEEE trans. Ind. Appl., vol. 27, no. 5, pp. 928-923.

[10] Tae-Won Chun, Quang-Vinh Tran, Hong-Hee, and Heung-Geun Kim, (2014), Sensorless Control of BLDC Motor Drive for an Automotive Fuel Pump Using a Hysteresis Comparator,IEEE trans. on power electronics, vol. 29, no. 3, pp. 1382 - 1391, ISSN :0885-8993.

[11] T.-H. Kim and M. Ehsani, (2004),Sensorless control of BLDC motors from near-zero to high speeds, IEEE Trans. Power Electron., vol. 19, no. 6,pp. 1635-1645.

[12] Kenjo T and S. Nagamori,(1985), "Permanent Magnet Brushless DC Motors", Clarendon Press, Oxford.

\section{BIOGRAPHIES}

Tinu Francis received her B.E. degree in Electrical and Electronics from Vimal Jyothi Engineering College,Kannur,Kerala,India in 2011. She is currently doing her M.E. in Power Electronics and Drives from SNS college of Engineering,Tamilnadu,India.Her research interest includes Power Electronics, Electric Drives and Control System. Also she has published 3 papers in national and international conferences.

Gokula Krishnan $\mathbf{P}$ received his B.E. degree in Electrical and Electronics from Kongu Engineering College,Erode,India in 2010.He Completed his M.E. in Embedded System from Coimbatore Institute of Technology ,Tamilnadu,India in 2013.Also he is having an industrial experience of one year as embedded software developer.His research interest includes Embedded system and Electrical Drives. Also he has published 2 papers in journal and international conference. 